\title{
Cloning, Characterization, and Evolution of the NBS-LRR-Encoding Resistance Gene Analogue Family in Polyploid Cotton (Gossypium hirsutum L.)
}

\author{
Limei He, ${ }^{1}$ Chunguang Du, ${ }^{2}$ Lina Covaleda, ${ }^{1}$ Zhanyou Xu, ${ }^{1}$ A. Forest Robinson, ${ }^{3}$ John Z. Yu, ${ }^{3}$ \\ Russell J. Kohel, ${ }^{3}$ and Hong-Bin Zhang ${ }^{1}$ \\ ${ }^{1}$ Department of Soil and Crop Sciences and Institute for Plant Genomics and Biotechnology, 2123 TAMU, Texas A\&M \\ University, College Station, U.S.A.; ${ }^{2}$ Department of Biology and Molecular Biology, Montclair State University, Upper \\ Montclair, NJ, U.S.A.; and ${ }^{3}$ USDA-ARS, SPARC, Cotton Pathology and Crop Germplasm Research Units, 2765 F\&B Road, \\ College Station, TX, U.S.A.
}

Submitted 22 April 2004. Accepted 29 July 2004.

The nucleotide-binding site-leucine-rich repeat (NBSLRR)-encoding gene family has attracted much research interest because approximately $75 \%$ of the plant disease resistance genes that have been cloned to date are from this gene family. We cloned the NBS-LRR-encoding genes from polyploid cotton by a polymerase chain reactionbased approach. A sample of $\mathbf{1 5 0}$ clones was selected from the NBS-LRR gene sequence library and was sequenced, and 61 resistance gene analogs (RGA) were identified. Sequence analysis revealed that RGA are abundant and highly diverged in the cotton genome and could be categorized into 10 distinct subfamilies based on the similarities of their nucleotide sequences. The numbers of members vary many fold among different subfamilies, and gene index analysis showed that each of the subfamilies is at a different stage of RGA family evolution. Genetic mapping of a selection of RGA indicates that the RGA reside on a limited number of the cotton chromosomes, with those from a single subfamily tending to cluster and two of the RGA loci being colocalized with the cotton bacterial blight resistance genes. The distribution of RGA between the two subgenomes $A$ and $D$ of cotton is uneven, with RGA being more abundant in the A subgenome than in the $D$ subgenome. The data provide new insights into the organization and evolution of the NBS-LRR-encoding RGA family in polyploid plants.

The genes encoding the nucleotide-binding site (NBS) and leucine-rich repeat (LRR) motifs constitute a large multigene family (hereafter referred to as the NBS-LRR gene family) in plants. In the past several years, more than 40 genes conferring resistance to different pathogens, including bacteria, fungi, nematodes, and viruses, have been cloned in plants. Of the cloned plant disease resistance $(R)$ genes, approximately $75 \%$ were from the NBS-LRR gene family (Hulbert et al. 2001). Therefore, isolation and characterization of the NBSLRR-encoding genes and determination of their organization and evolution in plant genomes are of significance for understanding of plant-pathogen interactions and development of

Corresponding author: H.-B. Zhang; Telephone: +979-862-2244; Fax: +979-862-4790; E-mail: hbz7049@tamu.edu novel approaches to effective control of plant pathogens in agriculture.

The NBS-LRR genes are abundant in plants. Whole-genome sequence analysis revealed that there are 150 to 175 NBS-LRR genes in the Arabidopsis genome (Dangl and Jones 2001; Meyers et al. 2003; Richly et al. 2002), constituting about $0.6 \%$ of its 25,000 genes (The Arabidopsis Genome Initiative 2000), and there are approximately 600 NBSLRR genes in the rice genome (Goff et al. 2002; Meyers et al. 1999), constituting about $1.5 \%$ of its 40,000 genes (Goff et al. 2002). According to the presence or absence of a TIR domain (Drosophila Toll and mammalian Interleukin-1 receptor homology region) at the $\mathrm{N}$ terminus of the protein, the NBS-LRR gene family is classified into two classes, the TIRNBS-LRR and non-TIR-NBS-LRR classes (Hulbert et al. 2001). Since similar genes were found in Rhizobia spp., yeasts, Drosophila spp., and vertebrates, in which they are involved in signal transduction pathways, the plant defense system is considered to be ancient and to predate the evolution of the vertebrate immune system (Hammond-Kosack and Jones 1997; Suominen et al. 2001; Van der Biezen and Jones 1998). The copy number of NBS-LRR genes might vary widely within a species, and the loci of the genes might rapidly rearrange (Leister et al. 1998).

Although the overall sequence homology of the NBS-LRR genes may vary significantly, several short motifs of their encoding proteins, such as NBS and LRR, are highly conserved. These conserved motifs have enabled rapid isolation of the NBS-LRR genes or resistance gene analogs (RGA) from different plant species by using a polymerase chain reaction (PCR)-based approach with degenerate oligonucleotide primers designed from these domains. RGA were isolated from several plant species, such as potato (Leister et al. 1996), soybean (Kanazin et al. 1996; Yu et al. 1996), lettuce (Shen et al. 1998), tomato (Ohmori et al. 1998; Pan et al. 2000), rice (Leister et al. 1998; Mago et al. 1999), barley (Leister et al. 1998; Seah et al. 1998), wheat (Seah et al. 1998; 2000), chickpea (Huettel et al. 2002), and Medicago truncatula (Zhu et al. 2002). Genetic mapping revealed that many of the RGA either cosegregate with or are closely linked to known disease resistance loci (Kanazin et al. 1996; Leister et al. 1996, 1998; Mago et al. 1999; Pan et al. 2000; Shen et al. 1998; Yu et al. 1996). Ramalingam and associates 
(2003) showed that, in rice, RGA are associated not only with qualitative resistance but also with quantitative response. These isolated RGA, thus, have provided useful tools to dissect, tag, and isolate genes conferring both qualitative and quantitative resistance to different pathogens. Nevertheless, little is known about how the NBS-LRR gene family as an entity is organized, functions, and evolves in plant genomes, especially in polyploid plant genomes.

Polyploid plants are widely distributed, constituting approximately $60 \%$ of flowering plants. Cottons are the leading textile fiber and the second most important oilseed in the world and have long been used as a model species for speciation, polyploidization, and evolutionary studies of polyploid plants. The genus Gossypium, to which cotton belongs, contains about 50 species, and the phylogeny among the species has been established (Seelanan et al. 1997; Small et al. 1998; Wendel 1989; Wendel and Albert 1992). Of these species, the two cultivated tetraploid species, G. hirsutum and G. barbadense, are diploidized allopolyploids containing A and D subgenomes, with each subgenome consisting of 13 chromosomes. The A and D subgenomes of the tetraploid cottons split from a common ancestor 6 to 11 million years ago (MYA) (Wendel 1989). The A and D genomes hybridized to form a tetraploid some 1 to 2 MYA, from which several tetraploid species, including $G$. hirsutum and $G$. barbadense, have evolved. While no $R$ genes or RGA have been reported in these species, they provide a desirable system for studies of organization and evolution of the NBS-LRR gene family in polyploid plants.

For this study, we cloned and sequenced a number of NBSLRR genes from the cultivated tetraploid cotton $G$. hirsutum and identified a number of the NBS-LRR RGA. Phylogenetic and gene index analyses were conducted to determine the relationships among the cotton RGA and cloned plant NBS-LRRencoding $R$ genes and to elucidate the evolution of the RGA family in the cotton genome. A selection of the RGA was mapped to an existing cotton genetic linkage map (Yu et al. 1998) to estimate their distribution in the two cotton subgenomes. These RGA clones provide not only useful markers for genetically mapping the disease resistance genes but also essential materials for studying the organization and evolution of the NBS-LRR gene family in this plant species.

\section{RESULTS}

\section{Cloning and analysis \\ of NBS-LRR-encoding gene sequences.}

We produced PCR products from cotton genomic DNA templates, using the degenerate primer pairs designed according to the NBS and membrane-spanning motifs of several cloned plant $R$ genes conferring resistance to bacteria, fungi, viruses, and nematodes that represented both TIR-NBS-LRR and non-TIR-NBS-LRR classes. The PCR products were analyzed on an agarose gel, and two bands were observed, one being about $560 \mathrm{bp}$ and the other about $700 \mathrm{bp}$ in size (Fig. 1). To further confirm the PCR amplification, different PCR conditions, including the concentrations of template DNA, $\mathrm{Mg}^{++}$, and Taq DNA polymerase, were tested. Although the 560-bp band could be reproduced under all conditions tested, the 700-bp band could not. Therefore, the 560bp band was excised from the gel and was cloned into the pGEM-T vector. More than 50 white clones were selected randomly from the library and were analyzed by PCR. The result showed that all of the clones had the expected insert sizes of about $560 \mathrm{bp}$ (data not shown), suggesting that the $560-\mathrm{bp}$ band was cloned properly. To facilitate further analysis, 768 recombinant clones of the library were arrayed as individual clones in two 384-well microplates.
To estimate the abundance and divergence of the NBSLRR-encoding RGA and their evolution in the cotton genome, 229 clones were randomly selected from the library and were sequenced. After the primers and vectors of the clones were removed, 150 of them had sequence reads of 500 bp or longer and, thus, were further analyzed against the GenBank database by Blastx search. Of the 150 clones, 62 were shown to have significantly high similarities (e-value < 0.001 ; Fig. 2) at the amino acid level to the cloned plant NBS-LRR-encoding $R$ genes, RGA, or both in the GenBank database. These clones were defined in this study as RGA and were further analyzed. To predict the abundance of the RGA in the cotton genome, the nucleotide sequences of the 62 RGA clones were analyzed using DNA Strider software (Marck 1988). Only one pair (2D13 and 2E15) of the 62 RGA clones (1.6\%) had identical sequences, which suggested that the NBS-LRR-encoding RGA are abundant in the cotton genome, although further study is needed to estimate the exact number of RGA.

To predict whether they are potentially functional, the sequences of the 61 different RGA clones were further analyzed by the GENESCAN program to search for ORF. Of the 61 RGA clones, $32(52.5 \%)$ had ORF of 100 or more amino acids, $14(23.0 \%)$ had ORF of 39 to 99 amino acids, and the remaining $15(24.6 \%)$ had no ORF, due to premature stop codons, frame-shift mutations, or both (Fig. 2). If the clones that had no ORF are considered to be pseudogenes (Deloukas et al. 2001; Kanazin et al. 1996; Mungall et al. 2003; Pan et al. 2000), only approximately $75 \%$ of the NBS-LRR-encoding RGA are potentially functional in the cotton genome.

\section{Phylogenetic analysis of the NBS-LRR-encoding RGA.}

To determine the relationships among the cotton RGA and cloned plant NBS-LRR-encoding $R$ genes, seven of the $R$ gene sequences, representing both TIR-NBS-LRR and non-TIRNBS-LRR classes and the non-NBS-LRR gene $C f$-5 (Hulbert et al. 2001), were downloaded from GenBank. The seven NBS-LRR-encoding $R$ genes were L6, Bs2, Gpa2, I2, Mil-2, $R P M 1$, and $R P S 2$. The $C f-5$ gene was used as an outgroup,

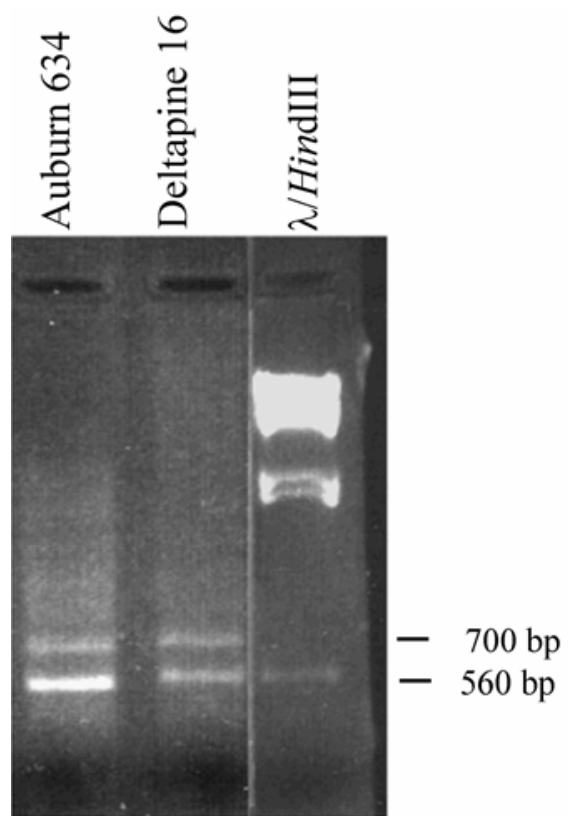

Fig. 1. Polymerase chain reaction products of genomic DNA of the cotton root-knot nematode resistance line Auburn 634 and the susceptible line Deltapine 16 using the nucleotide-binding site motif degenerate primers. The 560-bp band of Auburn 634 was cloned and analyzed in this study. 
although it does not encode the NBS motif. Then, multiple alignments were conducted among the 61 cotton RGA sequences, seven known NBS-LRR-encoding $R$ gene sequences, and the outgroup gene $C f-5$, using the ClustalX software. Ac- cording to the degree of similarity, 500-bp segments of the sequences were selected for phylogenetic analysis.

The phylogenetic analysis was carried out by use of the PAUP software. A total of 100 bootstrap runs were performed.

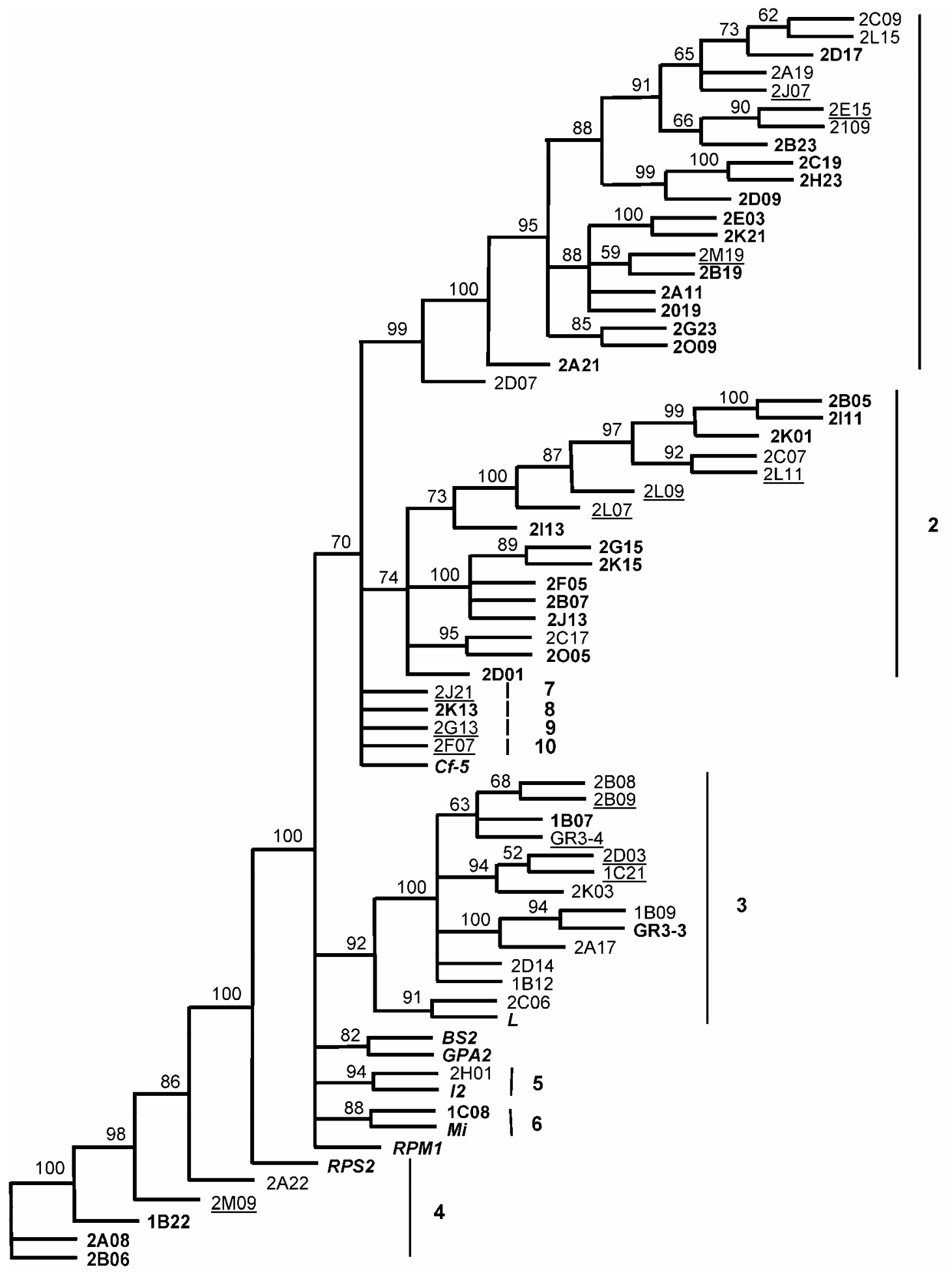

Fig. 2. Consensus tree of the cotton resistance gene analogs (RGA) constructed by phylogenic analysis using the PAUP package (Swofford 2001). The cotton nucleotide-binding site-leucine-rich repeat (NBS-LRR) RGA family is grouped into 10 subfamilies, each being indicated by bold-faced Arabic numbers 1 through 10. The genetic distances between clades (designated subfamilies) were $\geq 0.5512$, whereas the genetic distances within a clade were $\leq 0.5268$. The sequences in boldface could be translated into open reading frames (ORF) of 100 or more amino acids, the sequences underlined could be translated into ORF of 39 to 99 amino acids, and the sequences neither in boldface nor underlined could not be translated into ORF and were assumed to be pseudogenes. The numbers above the horizontal branches are the branch confidence in percentage, estimated by using the Felsenstein's bootstrap approach. The plant $R$ genes representing the NBS-LRR class selected from GenBank are italicized, and the LRR-transmembrane domain gene $C f-5$, cloned from tomato, was used as an outgroup (Hulbert et al. 2001). 
The consensus tree is shown in Figure 2, with the 50\% majority rule. The RGA were classified into 10 clades, designated subfamilies 1 through 10 , in 74 to 100 of the 100 bootstrap replicates. The genetic distances between pairs of the RGA ranged from 0.0096 between $2 \mathrm{~B} 07$ and $2 \mathrm{~J} 13$ to 0.7569 between $2 \mathrm{D} 07$ and $2 \mathrm{~A} 22$, with $\geq 0.5512$ between clades and $\leq 0.5268$ within a clade. Clades $1,2,3$, and 4 each consisted of five or more members of the 61 RGA, whereas clades 5 through 10 each consisted of only one or two members of the 61 RGA, suggesting that the abundance of each RGA subfamily in the cotton genome was significantly different. Among the four largest subfamilies, clade 2 had the greatest withingenetic divergence, with the genetic distances between its subclades being around 0.5000 .

To estimate the evolutionary status of each subfamily consisting of five or more RGA, the percentages of the RGA that had no ORF were calculated. Only two $(12.5 \%)$ of the 16 RGA in clade 2 had no ORF, whereas $20.0 \%$ of the RGA in clade 4 had no ORF, $23.2 \%$ in clade 1 , and $46.2 \%$ in clade 3 . The percentage of the clones in clade 2 having no ORF was lower by twofold than the mean of the entire RGA family (24.6\%), whereas that in clade 3 was higher than the mean of the entire RGA family by about twofold.
Of the seven cloned NBS-LRR-encoding $R$ genes included in the phylogenetic analysis, four, $I_{2}, M i, R P S 2$, and $L$, each were claded with one or more cotton NBS-LRR-encoding RGA. The $L$ gene representing the TIR-NBS-LRR-encoding $R$ genes was claded in the clade 3 , and the $R P S 2, M i$, and $I_{2}$ genes representing the non-TIR-NBS-LRR-encoding $R$ genes (Hulbert et al. 2001) were claded in clades 4, 5, and 6, respectively. To further explore the similarity of the cotton RGA to the cloned NBS-LRR-encoding $R$ genes in the clades, multiple alignments among them were conducted at the amino acid sequence level, using the ClustalX program (Fig. 3). The result showed that the RGA and NBS-LRR-encoding $R$ genes also had high similarities at the amino acid sequence level, though variations were observed.

\section{Genetic mapping of RGA.}

To estimate the distribution of NBS-LRR-encoding RGA in the two subgenomes of the cotton genome, 22 of the 62 RGA were selected and surveyed for polymorphism between the two parents, G. hirsutum TM-1 and G. barbadense 3-79, of the mapping population of an existing cotton genetic map ( $\mathrm{Yu}$ et al. 1998). A total of 15 from subfamilies (clades) 1 (3 RGA), 3 (9 RGA), 4 (2 RGA), and 6 (1 RGA), respectively, were found to
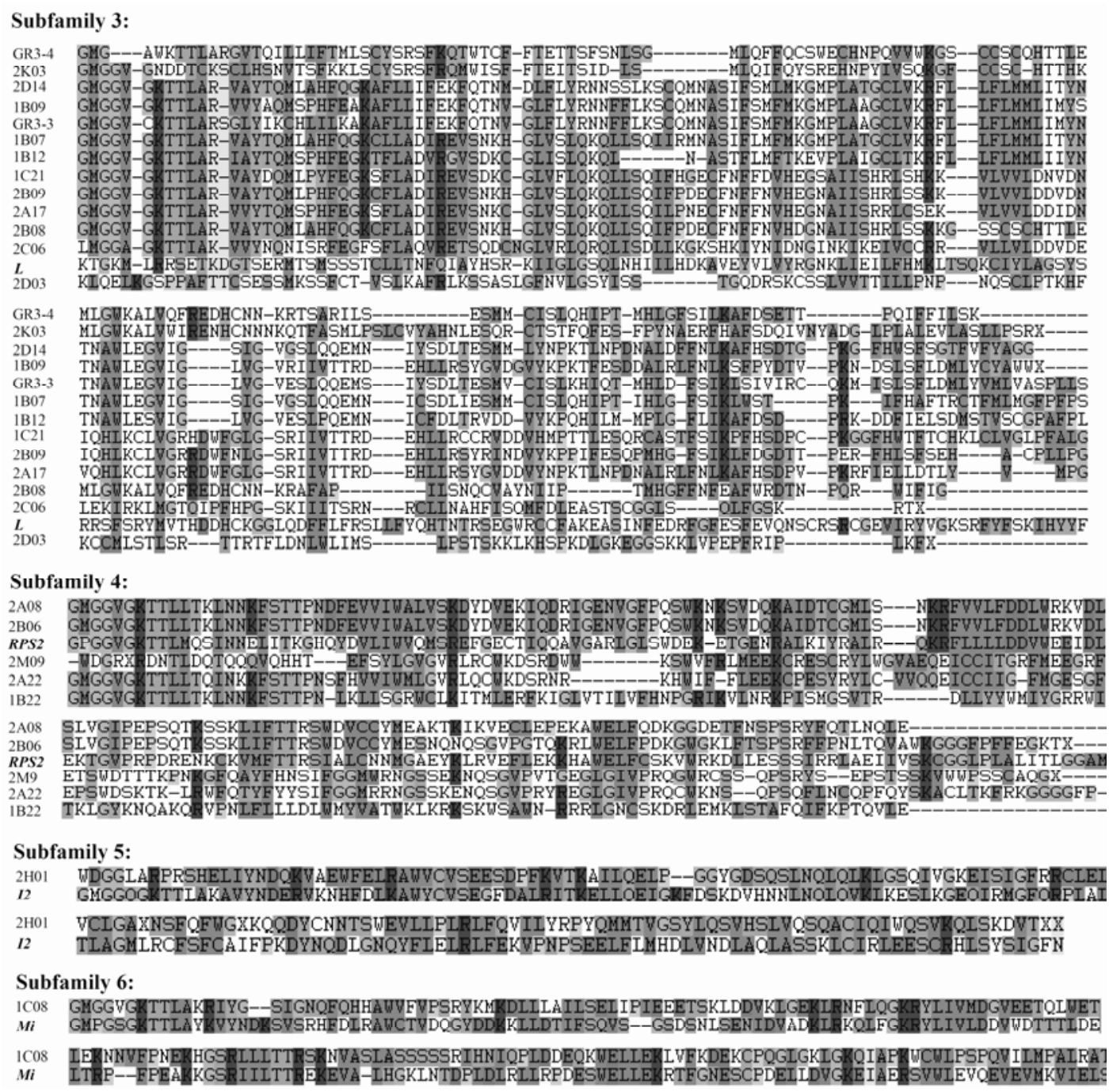

Fig. 3. Multiple sequence alignment of the cotton nucleotide-binding site-leucine-rich repeat (NBS-LRR) resistance gene analog (RGA) subfamilies claded with known plant NBS-LRR-encoding $R$ genes. The amino acid sequences corresponding to the 500-bp nucleotides of the RGA and known NBS-LRRencoding $R$ genes starting from the NBS motif were used in the alignment by ClustalX. The motifs of the amino acid sequences are highlighted by the ClustalX program. The known NBS-LRR-encoding $R$ genes are $L$ for subfamily $3, R P S 2$ for subfamily $4, I_{2}$ for subfamily 5 , and $M i$ for subfamily 6 . 
be polymorphic and thus mapped to the cotton genetic map. The genetic distances and relative positions of the clones in the cotton genetic map (Yu et al. 1998) are shown in Figure 4. In total, 16 polymorphic fragments derived from the 15 RGA were mapped to seven of the 26 chromosomes or linkage groups of the cotton A and D subgenomes, with four, named A1, A3, A4, and Chr., 6 belonging to the A subgenome and three, named chromosomes $17,20 \mathrm{~b}$, and 23 , belonging to the D subgenome. Of the 16 RGA polymorphic fragments, nine were mapped to a single linkage group, A4 of the subgenome A, two to chromosome 23 , and one to each of chromosomes or linkage groups $\mathrm{A} 1, \mathrm{~A} 3,6,17$, and 20b. Two polymorphic fragments (2A22a and $2 \mathrm{~A} 22 \mathrm{~b}$ ) identified by probe $2 \mathrm{~A} 22$ were mapped to different subgenomes, one (2A22a) to a chromosome (chromosome 6 ) of the A subgenome and the other (2A22b) to a chromosome (chromosome 23) of the D subgenome. Since no disease resistance genes were mapped to the genetic map (Yu et al. 1998) that was used in this experiment, we conducted a literature search to infer the relationships between the mapped loci of the RGA and the known disease resistance loci. As a result, although few disease resistance genes were mapped in cotton (Wright et al. 1998), the RGA of linkage group A4 were colocalized with a quantitative trait locus (QTL) conferring resistance to the cotton bacterial blight pathogen Xanthomonas campestris pv. malvacearum (Smith) Dye, and that of chromosome 20b was likely colocalized with one of the two bacterial blight resistance gene loci mapped to the chromosome.

\section{DISCUSSION}

We successfully cloned the NBS-LRR-encoding gene sequences from the cotton genome with PCR, by use of the degenerate oligonucleotide primers designed from the NBS regions of several NBS-LRR-encoding $R$ genes cloned in several diverged plant species (Hulbert et al. 2001). Sequence analysis of 150 clones randomly selected from the DNA library revealed that $62(41.3 \%)$ have significant similarities to cloned plant NBS-LRR-encoding $R$ genes and RGA in the GenBank. The fact that only two of the 62 RGA were shown to be identical in sequences suggests that RGA are abundant in the cotton genome. These results agree with the findings discovered by whole genome sequencing in the genomes of Arabidopsis (Richly et al. 2002; Meyer et al. 2003) and rice (Goff et al. 2002), which contain about 150 and 600 NBS-LRR RGA, respectively. Genetic mapping of 16 RGA showed that these NBS-LRR-encoding RGA reside at a limited number of the 26 cotton chromosomes, which is consistent with findings in other plant species (Kanazin et al. 1996; Mago et al. 1999; Yu et al. 1996). Of these RGA, 56\% mapped to a single linkage group of the A subgenome (A4). The colocalization of the cotton RGA mapped to this linkage group (A4) and chromosome $20 \mathrm{~b}$ with the previously mapped cotton bacterial blight $(X$. campestris pv. malvacearum) resistance loci (Wright et al. 1998) suggests that these RGA may be involved in the bacterial blight resistance.

$G$. hirsutum and $G$. barbadense are diploidized allopolyploid species containing A and D subgenomes. Distribution of RGA between the two subgenomes seems biased. This study showed that the RGA are more abundant in the A subgenome than in the D subgenome, since 12 of the 16 RGA sequences mapped to the A subgenome, whereas only four of them mapped to the D subgenome. Further investigation is needed to test whether the difference in abundance of RGA between the two subgenomes of the polyploid species is due to sampling, different genome sizes (the A subgenome is about twofold larger than the D subgenome), evolutionary drive, or any or all of these in combination. The genetic mapping of RGA also suggests that the RGA that share higher similarities or from a single subfamily tend to cluster in the genome, although some of them may reside at different loci of the genome. This is supported in this study by genetic mapping of the members selected from subfamilies 1,3 , and 4 .

The RGA gene family is widely divergent in the cotton genome. High genetic divergence was found between the 61
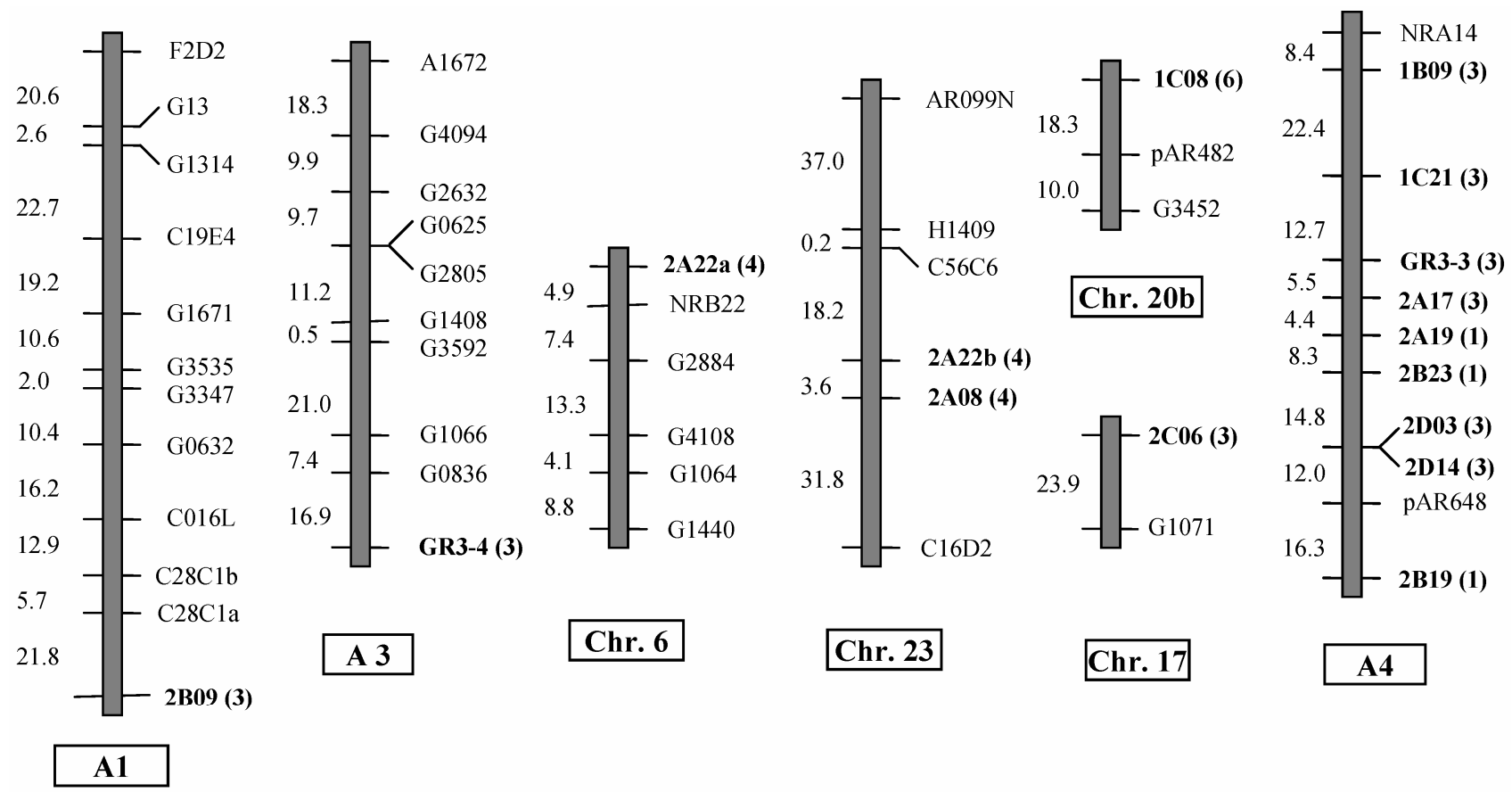

Chr. 23

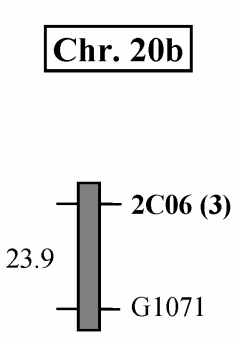

Chr. 17

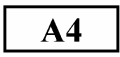

Fig. 4. Distribution of cotton nucleotide-binding site-leucine-rich repeat resistance gene analogs (RGA) in the cotton genetic map (Yu et al. 1998). The names in boldface indicate the cotton RGA cloned in this study, of which two polymorphic fragments of 2 A22, indicated by "a" and "b", respectively, were mapped. The linkage groups of the cotton genetic map are named by their corresponding chromosomes, whenever relevant data are available, or subgenomic origins (A or D) of polyploid cotton. The numbers in parentheses behind each RGA indicate the subfamily from which the RGA is derived. 
RGA in this study at the nucleotide sequence level. This may suggest that the cotton RGA are ancient and have evolved rapidly. The former hypothesis seems supported by the fact that four of the 10 cotton NBS-LRR-encoding RGA subfamilies (3, 4, 5, and 6) were claded with four NBS-LRR-encoding $R$ genes, $L, R P S 2, M i$, and $I_{2}$, cloned from three different species, flax, Arabidopsis, and tomato, of diverged dicot plant species, indicating that the cotton RGA and NBS-LRR-encoding $R$ genes may share ancestors. Nevertheless, it is also possible that the clade of the cotton RGA with the $L, R P S 2, M i$, and $I_{2}$ genes might result from convergent evolution that mimicks orthology of the cotton RGA. The rapid evolution of the cotton NBS-LRR RGA seems to have been supported by the formation of the diverged subfamilies and the fact that the two largest subfamilies (1 and 2) were not claded with any of the seven NBS-LRR-encoding $R$ genes included in the phylogenetic analysis.

The cotton NBS-LRR RGA family consists of at least 10 distinct subfamilies. This classification is supported by high bootstrap resampling ( $>90 \%$ for all subfamilies but subfamily 2 ). The number of subfamilies is similar to that observed in other species such as soybean (Kanazin et al. 1996; Yu et al. 1996), but it is possible that additional subfamilies may be found when additional RGA clones are sequenced. Nevertheless, the abundance of each subfamily in the cotton genome is significantly different, varying from 1 to 21 of the 61 RGA analyzed, and more than one third of the RGA are contributed by a single subfamily (1). Another significant feature of the classification is that six of the 10 subfamilies each consist of only one or two of the RGA analyzed. This difference may reflect, at least in part, the status of each subfamily in the course of RGA family evolution. For instance, the subfamilies 1 and 4 may be at the plateau of its evolution, while the subfamilies 2, 3 , and 5 through 10 may be at incipient, degenerative, or vestigial stages (discussed below). Alternatively, a unique abundance for each RGA subfamily in the cotton genome may be associated with the functions of the genes represented by the RGA, host-pathogen interactions, or both.

Gene index analysis of the RGA further supports the above hypothesis that each subfamily of the NBS-LRR RGA family is at an independently determined stage of RGA family evolution in the cotton genome. Because 15 of the 61 different RGA analyzed do not have ORF due to stop codons, frame-shift mutations, or both, approximately one fourth of the RGA are likely to be pseudogenes. This number is in agreement with those identified in the human genome in general (Deloukas et al. 2001; Mungall et al. 2003). Although RGA pseudogenes were previously observed in soybean ( 1 of $9=11.1 \%$; Kanasin et al. 1996), tomato ( 7 of $75=9.3 \%$; Pan et al. 2000) and Arabidopsis (approximately 10\%; Meyers et al. 2003), the ratio of pseudogenes $(24.6 \%)$ observed in the polyploid cotton in this study is much higher. In comparison, Arabidopsis and tomato are both diploid and soybean is a diploidized ancient tetraploid, while cotton is a diploidized allopolyploid. Thus, the level of the ploidy might play a role in the accumulation of pseudogenes in the genomes. From this point of view, the subfamilies of the RGA family that have a lower ratio of pseudogenes than the mean for the entire family may be at evolving stages, while those that have a higher ratio of pseudogenes may be at degenerative stages. Based on this criterion, two of the 10 cotton RGA subfamilies ( 3 and 5) are likely to be at degenerative stages, six $(2,6,7,8,9$, and 10) are at incipient or evolving stages, and two (1 and 4) are at stable stages.

NBS-encoding RGA have been cloned from several plant species and colocalized with many known resistance genes loci, including those for qualitative and quantitative resistance. In this study, the RGA mapped to linkage group A4 were colo- calized with a QTL, and that of chromosome 20b was colocalized with a gene locus of the cotton bacterial blight resistance previously mapped (Wright et al. 1998), suggesting that the NBS-LRR-encoding RGA may be involved in both qualitative and quantitative resistance in cotton. Therefore, the cotton RGA isolated in this study will provide useful tools for developing DNA markers and cloning the genes for resistance to different pathogens in cotton, in which few studies have previously been conducted. The marker development can be accomplished by genetic mapping of the RGA against the known resistance genes, and the NBS-LRR-encoding $R$ genes can be isolated by positional cloning, using a whole-genome BAC/BIBAC-based integrated physical and genetic map of the cotton genome, under development in our laboratories. Moreover, traditionally, cotton is a model species for studies of speciation, polyploidization, and evolution in polyploid plants. The cloned cotton RGA will promote studies of organization, function, and evolution of the NBS-LRR-encoding gene family in polyploid plants representing about $60 \%$ of flowering plants.

\section{MATERIALS AND METHODS}

\section{Plant materials and genomic DNA exaction.}

The cotton root-knot nematode resistance line Auburn 634 G. hirsutum, was used as DNA source for NBS-LRR gene sequence cloning. The G. hirsutum genetic standard line TM$1, G$. barbadense genetic standard line 3-79, and the population of the TM-1 $\times 3-79$ cross containing $171 \mathrm{~F}_{2}$ plants were used to genetically map the cloned RGA, to estimate their distribution between the cotton A and D subgenomes (Yu et al. 1998). Genomic DNA was isolated from fresh or frozen leaf tissues, using a cetytrimethylammonium bromide method (Doyle and Doyle 1990) with minor modifications.

\section{NBS-LRR gene sequence cloning.}

The NBS-LRR gene sequences were cloned by a PCR-based approach, using the genomic DNA of cotton root-knot nematode resistance line Auburn 634 and susceptible line Deltapine 16 as templates and a pair of degenerate sequences of several cloned plant NBS-LRR-encoding $R$ genes as primers. The design of the degenerate primers was based on the NBS and membrane-spanning motif sequences of two cloned $R$ genes, $N$ and $L 6$, from the TIR-NBS-LRR class and three cloned $R$ genes, RPS2, RPM1, and Cre, from the non-TIR-NBS-LRR class (Hulbert et al. 2001). RPS2 and RPM1 are the bacterial resistance genes in Arabidopsis, $N$ is a viral resistance gene in tobacco, $L 6$ is a fungal resistance gene of flax, and Cre is the cyst nematode resistance gene candidate of Aegilope tauschii (Lagudah et al. 1997). The forward primer F1 was designed in sense direction, corresponding to the amino acid sequence GMGGVGKT of the NBS motif: 5'-GGNATGGGNGGNGTN GGNAA(A/G)AC-3', and the reverse primer R1 was based on the amino acid sequence GLPLALKV of the membrane-spanning motif in anti-sense direction: 5'-AC(T/C)TTNA (A/G) NGCNA(A/G)NGGNA(A/G)NCC-3'.

PCR reaction was carried out in a volume of $50 \mu$ l containing $25 \mathrm{ng}$ of genomic DNA, $130 \mu \mathrm{M}$ dNTPs, $15 \mu \mathrm{M}$ each primer, 2.5 units Taq polymerase, and $1 \times$ PCR reaction buffer (Life Technologies, Rockville, MD, U.S.A.) with $1.5 \mathrm{mM}$ $\mathrm{MgCl}_{2}$. The reaction conditions were $3 \mathrm{~min}$ at $94^{\circ} \mathrm{C}$, followed by 30 cycles of denaturing at $94^{\circ} \mathrm{C}$ for $1 \mathrm{~min}$, annealing at $45^{\circ} \mathrm{C}$ for $1 \mathrm{~min}$, and elongating at $72^{\circ} \mathrm{C}$ for $2 \mathrm{~min}$. Finally, the reaction was incubated at $72^{\circ} \mathrm{C}$ for an additional $7 \mathrm{~min}$. The PCR product was separated by electrophoresis on a $1.2 \%$ (wt/vol) agarose gel. Desired bands were excised from the gel, and the DNA was purified, using the Prep-A-Gene kit (BioRad, Hercules, CA, U.S.A.) and cloned in the pGEM-T vector 
(Promega, Madison, WI, U.S.A.). Recombinant DNA was transferred into Escherichia coli DH10B strain cells by electroporation and was plated on the Luria Broth (LB) agar blue and white selective medium. The white colonies having inserts were selected, were arrayed as individual clones in 384-well microplates containing freezing medium (Zhang et al. 1996) plus $50 \mathrm{mg}$ of ampicillin per liter, and were maintained in $-80^{\circ} \mathrm{C}$ freezers.

\section{DNA sequencing and analysis.}

Clones were randomly selected from the NBS-LRR gene sequence library and were grown overnight in LB medium containing $50 \mathrm{mg}$ of ampicillin per liter. Plasmid DNA was purified according to the alkaline lysis method (Sambrook et al. 1989) and was sequenced from one or both strands, using the ABI PRISM BigDye terminator cycle sequencing ready reaction kit (Applied Biosystems, Foster City, CA, U.S.A.) with M13 forward or reverse primer. Sequences of the PCR product were determined on the ABI PISM 377 DNA sequencer (Applied Biosystems). Sequences were edited manually to further verify the sequence and, using GeneDoc software, to remove the primer and vector sequences. Database searches were performed using the National Center for Biotechnology Information Center's Blastx to search the similarity of the RGA to the NBS-LRR-encoding $R$ genes and RGA cloned in plants, with an e-value $<0.001$ considered as hits. RGA sequences of $500 \mathrm{bp}$ or longer were analyzed in gene index, according to Deloukas and associates (2001) and Mungall and associates (2003), using the GENSCAN program (Burge and Karlin 1997). The RGA sequences that did not give ORF were defined as "pseudogenes," according to Deloukas and associates (2001) and Mungall and associates (2003).

\section{Phylogenetic analysis.}

The alignment of the RGA clones was based on 500-bp nucleotide sequences, starting from the NBS motif between the degenerate sequence primer pair. The sequences were used for phylogenetic analysis to construct the phylogenetic tree of the RGA with the PAUP package version $4.0 \mathrm{~b} 10$ (Swofford 2001). The Felsenstein's bootstrap method was employed to evaluate the reliability of each branch of the tree. Also included in the phylogenetic analysis were the sequences of corresponding regions of the following cloned $R$ genes: L6 (U27081), RPS2 (U12860), Bs2 (AF202179), GPA2 (AF195939), Mi1-2 (AF039682), I2C-1 (AF004878), RPMI (X87851), and Cf-5 (AF053993). The $L$ gene belongs to the TIR-NBS-LRR class, whereas RPS2, Bs2, GPA2, Mil-2, I2C-1, and RPM1 represent the non-TIR-NBS-LRR gene class. The $C f-5$ gene does not belong to the NBS-LRR genes, but it does encode the LRR motif, which was used as an outgroup in the experiment. The nucleotide sequences of the cotton NBS-LRR RGA have been deposited in the GenBank under accession numbers: AY600372 to AY600433. The clades (designating the subfamilies of the NBS-LRR RGA gene family) that showed significant similarities to cloned plant NBS-LRR-encoding $R$ genes were further analyzed at the amino acid sequence level using ClustalX (Thompson et al. 1997). This computer program provides an integrated environment for performing multiple sequence and profile alignments.

\section{Genetic mapping.}

The standard restriction fragment length polymorphism mapping procedure was used to map RGA to an existing cotton genetic map, using the $G$. hirsutum TM- $1 \times G$. barbadense 3-79 mapping population containing $171 \mathrm{~F}_{2}$ plants ( $\mathrm{Yu}$ et al. 1998). Four restriction enzymes, EcoRI, EcoRV, HindIII, and $X b a \mathrm{I}$, were used to digest genomic DNA of both parents to prepare Southern blots for polymorphism survey and DNA of the $F_{2}$ plants to prepare the Southern blots for mapping. Southern blot hybridization was carried out at $65^{\circ} \mathrm{C}$, using the purified insert DNA of the RGA clones as probes. After hybridization, the filters were washed three times in $1 \times$ SSC $(1 \times$ SSC is $0.15 \mathrm{M} \mathrm{NaCl}$ plus $0.015 \mathrm{M}$ sodium citrate) (Sambrook et al. 1989), $0.1 \%$ (wt/vol) sodium dodecyl sulfate at $65^{\circ} \mathrm{C}, 30 \mathrm{~min}$ each wash. The polymorphic bands of each clone were mapped on the existing cotton genetic map (Yu et al. 1998) with MAPMAKER 3.0b (Lander et al. 1987), using a log of the likelihood ratio threshold of 4.0 and the Kasambi mapping function.

\section{ACKNOWLEDGMENTS}

This study was supported in part by a grant of the Texas Cotton Biotechnology Initiative and Texas Agricultural Experiment Station (8536203232).

\section{LITERATURE CITED}

The Arabidopsis Genome Initiative. 2000. Analysis of the genome sequence of the flowering plant Arabidopsis thaliana. Nature 408:796-815.

Burge, C., and Karlin, S. 1997. Prediction of complete gene structures in human genomic DNA. J. Mol. Biol. 268:78-94.

Dangl, J. L., and Jones, J. D. 2001. Plant pathogens and integrated defense responses to infection. Nature 411:826-833.

Deloukas, P., Matthews, L. H., Ashurst, J., Burton, J., Gilbert, J. G. R., Jones, M., Stavrides, G., Almeida, J. P., Babbage, A. K., Bagguley, C. L., Bailey, J., Barlow, K. F., Bates, K. N., Beard, L. M., Beare, D. M., Beasley, O. P., Bird, C. P., Blakey, S. E., Bridgeman, A. M., Brown, A. J., Buck, D., Burrill, W., Butler, A. P., Carder, C., Carter, N. P., Chapman, J. C., Clamp, M., Clark, G., Clark, L. N., Clark, S. Y., Clee, C. M., Clegg, S., Cobley, V. E., Collier, R. E., Connor, R., Corby, N. R., Coulson, A., Coville, G. J., Deadman, R., Dhami, P., Dunn, M., Ellington, A. G., Frankland, J. A., Fraser, A., French, L., Garner, P., Grafham, D. V., Griffiths, C., Griffiths, M. N. D., Gwilliam, R., Hall, R. E., Hammond, S., Harley, J. L., Heath, P. D., Ho, S., Holden, J. L., Howden, P. J., Huckle, E., Hunt, A. R., Hunt, S. E., Jekosch, K., Johnson, C. M., Johnson, D., Kay, M. P., Kimberley, A. M., King, A., Knights, A., Laird, G. K., Lawlor, S., Lehvaslaiho, M. H., Leversha, M., Lloyd, C., Lloyd, D. M., Lovell, J. D., Marsh, V. L., Martin, S. L., Mcconnachie, L. J., Mclay, K., Mcmurray, A. A., Milne, S., Mistry, D., Moore, M. J. F., Mullikin, J. C., Nickerson, T., Oliver, K., Parker, A., Patel, R., Pearce, T. A. V., Peck, A. I., Phillimore, B. J. C. T., Prathalingam, S. R., Plumb, R. W., Ramsay, H., Rice, C. M., Ross, M. T., Scott, C. E., Sehra, H. K., Shownkeen, R., Sims, S., Skuce, C. D., Smith, M. L., Soderlund, C., Steward, C. A., Sulston, J. E., Swann, M., Sycamore, N., Taylor, R., Tee, L., Thomas, D. W., Thorpe, A., Tracey, A., Tromans, A. C., Vaudin, M., Wall, M., Wallis, J. M., Whitehead, S. L., Whittaker, P., Willey, D. L., Williams, L., Williams, S. A., Wilming, L., Wray, P. W., Hubbard, T., Durbin, R. M., Bentley, D. R., Beck, S., and Rogers, J. 2001. The DNA sequence and comparative analysis of human chromosome 20. Nature 414:865-871.

Doyle, J. J., and Doyle, J. L. 1990. Isolation of plant DNA from fresh tissue. Focus 12:13-15.

Goff, S. A., Ricke, D., Lan, T. H., Presting, G., Wang, R., Dunn, M. Glazebrook, J., Sessions, A., Oeller, P., Varma, H., Hadley, D., Hutchison, D., Martin, C., Katagiri, F., Lange, B. M., Moughamer, T., Xia, Y., Budworth, P., Zhong, J., Miguel, T., Paszkowski, U., Zhang, S., Colbert, M., Sun, W. L., Chen, L., Cooper, B., Park, S., Wood, T. C., Mao, L., Quail, P., Wing, R., Dean, R., Yu, Y., Zharkikh, A., Shen, R., Sahasrabudhe, S., Thomas, A., Cannings, R., Gutin, A., Pruss, D., Reid, J., Tavtigian, S., Mitchell, J., Eldredge, G., Scholl, T., Miller, R. M., Bhatnagar, S., Adey, N., Rubano, T., Tusneem, N., Robinson, R., Feldhaus, J., Macalma, T., Oliphant, A., and Briggs, S. 2002. A draft sequence of the rice genome (Oryza sativa L. ssp. japonica). Science 296:79-92.

Hammond-Kosack, K. E., and Jones, J. D. G. 1997. Plant disease resistance genes. Ann. Rev. Plant Physiol. Plant Mol. Biol. 48:575-607.

Huettel, B., Santra, D., Muehlbauer, F. J., and Kahl, G. 2002. Resistance gene analogues of chickpea (Cicer arietinum L.): Isolation, genetic mapping and association with a Fusarium resistance gene cluster. Theor. Appl. Genet. 105:479-490.

Hulbert, S. H., Webb, C. A., Smith, S. M., and Sun, Q. 2001. Resistance gene complexes: Evolution and utilization. Ann. Rev. Phytopathol. 39:285-312. 
Kanazin, V., Marek, L. F., and Shoemaker, R. C. 1996. Resistance gene analogs are conserved and clustered in soybean. Proc. Natl. Acad. Sci. U.S.A. 93:11746-11750.

Lagudah, E. S., Moullet, O., and Appels, R. 1997. Map-based cloning of a gene sequence encoding a nucleotide-binding domain and a leucinerich region at the $\mathrm{Cre} 3$ nematode resistance locus of wheat. Genome 40:659-665

Lander, E. S., Green, P., Abrahamson, J., Barlow, A., Daly, M. J., Lincoin, S. E., and Newburg, L. 1987. MAPMAKER: An interactive computer package for constructing primary genetic linkage maps of experimental and natural populations. Genomics 1:174-181.

Leister, D., Ballvora, A., Salamini, F., and Gebhardt, C. 1996. A PCRbased approach for isolating pathogen resistance genes from potato with potential for wide application in plants. Nat. Genet. 14:421-429.

Leister, D., Kurth, J., Laurie, D. A., Yano, M., Sasaki, T., Devos, K., Graner, A., and Schulze-Lefert, P. 1998. Rapid reorganization of resistance gene homologues in cereal genomes. Proc. Natl. Acad. Sci. U.S.A. 95:370 375 .

Mago, R., Nair, S., and Mohan, M. 1999. Resistance gene analogues from rice: Cloning, sequencing and mapping. Theor. Appl. Genet. 99:50-57.

Marck, C. 1988. "DNA Strider": A "C" program for the fast analysis of DNA and protein sequences on the Apple Macintosh family of computers. Nucleic Acids Res. 16:1829-1836.

Meyers, B. C., Dickerman, A. W., Michelmore, R. W., Sivaramakrishnan, S., Sobral, B. W., and Young, N. D. 1999. Plant disease resistance genes encode members of an ancient and diverse protein family within the nucleotide-binding superfamily. Plant J. 20:317-332.

Meyers, B.C., Kozik, A., Griego, A., Kuang, H., and Michelmore, R. W. 2003. Genome-wide analysis of NBS-LRR-encoding genes in Arabidopsis. Plant Cell 15:809-834.

Mungall, A. J., Palmer, S. A., Sims, S. K., Edwards, C. A., Ashurst, J. L., Wilming, L., Jones, M. C., Horton, R., Hunt, S. E., Scott, C. E., Gilbert, J. G. R., Clamp, M. E., Bethel, G., Milne, S., Ainscough, R., Almeida, J. P., Ambrose, K. D., Andrews, T. D., Ashwell, R. I. S., Babbage, A. K., Bagguley, C. L., Bailey, J., Banerjee, R., Barker, D. J., Barlow, K. F., Bates, K., Beare, D. M., Beasley, H., Beasley, O., Bird, C. P., Blakey, S., Bray-Allen, S., Brook, J., Brown, A. J., Brown, J. Y., Burford, D. C., Burrill, W., Burton, J., Carder, C., Carter, N. P., Chapman, J. C., Clark, S. Y., Clark, G., Clee, C. M., Clegg, S., Cobley, V., Collier, R. E., Collins, J. E., Colman, L. K., Corby, N. R., Coville, G. J., Culley, K. M., Dhami, P., Davies, J., Dunn, M., Earthrowl, M. E., Ellington, A. E., Evans, K. A., Faulkner, L., Francis, M. D., Frankish, A., Frankland, J., French, L., Garner, P., Garnett, J., Ghori, M. J. R., Gilby, L. M., Gillson, C. J., Glithero, R. J., Grafham, D. V., Grant, M., Gribble, S., Griffiths, C., Griffiths, M., Hall, R., Halls, K. S., Hammond, S., Harley, J. L., Hart, E. A., Heath, P. D., Heathcott, R., Holmes, S. J., Howden, P. J., Howe, K. L., Howell, G. R., Huckle, E., Humphray, S. J., Humphries, M. D., Hunt, A. R., Johnson, C. M., Joy, A. A., Kay, M., Keenan, S. J., Kimberley, A. M., King, A., Laird, G. K., Langford, C., Lawlor, S., Leongamornlert, D. A., Leversha, M., Lloyd, C. R., Lloyd, D. M. Loveland, J. E., Lovell, L., Martin, S., Mashreghi-Mohammadi, M., Maslen, G.L, Matthews, L., Mccann, O. T., Mclaren, S. J., Mclay, K., Mcmurray, A., Moore, M. J. F., Mullikin, J. C., Niblett, D., Nickerson, T., Novik, K. L., Oliver, K., Overton-Larty, E. K., Parker, A., Patel, R., Pearce, A. V., Peck, A. I., Phillimore, B., Phillips, S., Plumb, R. W. Porter, K. M., Ramsey, Y., Ranby, S. A., Rice, C. M., Ross, M. T., Searle, S. M., Sehra, H. K., Sheridan, E., Skuce, C. D., Smith, S., Smith, M., Spraggon, L., Squares, S. L., Steward, C. A., Sycamore, N., Tamlyn-Hall, G., Tester, J., Theaker, A. J., Thomas, D. W., Thorpe, A., Tracey, A., Tromans, A., Tubby, B., Wall, M., Wallis, J. M., West, A. P., White, S. S., Whitehead, S. L., Whittaker, H., Wild, A., Willey, D. J., Wilmer, T. E., Wood, J. M., Wray, P. W., Wyatt, J. C., Young, L. Younger, R. M., Bentley, D. R., Coulson, A., Durbin, R., Hubbard, T., Sulston, J. E., Dunham, I., Rogers, J., and Beck, S. 2003. The DNA sequence and analysis of human chromosome 6. Nature 425:805-811.

Ohmori, T., Murata, M., and Motoyoshi, F. 1998. Characterization of disease resistance gene-like sequences in near-isogenic lines of tomato. Theor. Appl. Genet. 96:331-338.

Pan, Q., Wendel, J., and Fluhr, W. 2000. Divergent evolution of plant NBS-LRR resistance gene homologues in dicot and cereal genomes. J. Mol. Evol. 50:203-213.

Ramalingam, J., Vera Cruz, C. M., Kukreja, K., Chittoor, J. M., Wu, J.-L., Lee, S. W., Baraoidan, M., George, M. L., Cohen, M. B., Hulbert, S. H.,
Leach, J. E., and Leung, H. 2003. Candidate defense genes from rice, barley, and maize and their association with qualitative and quantitative resistance in rice. Mol. Plant-Microbe Interact. 16:14-24.

Richly, E., Kurth, J., and Leister, D. 2002. Mode of amplification and reorganization of resistance genes during recent Arabidopsis thaliana evolution. Mol. Biol. Evol. 19:76-84.

Sambrook, J., Fritsch, E. F., and Maniatis, T. 1989. Molecular cloning: A Laboratory Manual, 2nd ed. Cold Spring Harbor Laboratory Press, Cold Spring Harbor, NY, U.S.A.

Seah, S., Sivasithamparam, K., Karakousis, A., and Lagudah, E. S. 1998 Cloning and characterisation of a family of disease resistance gene analogs from wheat and barley. Theor. Appl. Genet. 97:937-945.

Seah, S., Spielmeyer, W., Jahier, J., Sivvvasithamparam, K., and Lagudah, E. S. 2000. Resistance gene analogs within an introgressed chromosomal segment derived from Triticum ventricosum that confers resistance to nematode and rust pathogens in wheat. Mol. Plant-Microbe Interact. 13:334-341.

Seelanan, T., Schnabel, A., and Wendel, J. F. 1997. Congruence and consensus in the cotton tribe. Syst. Bot. 22:259-290.

Shen, K. A., Meyers, B. C., Islam-Faridi, M. N., Chin, D. B., Stelly, D. M., and Michelmore, R. W. 1998. Resistance gene candidates identified by PCR with degenerate oligonucleotide primers map to clusters of resistance genes in lettuce. Mol. Plant-Microbe Interact. 11:815823.

Small, R. L., Ryburn, J. A., Cronn, R. C., Seelanan, T., and Wendel, J. F. 1998. The tortoise and the hare: Choosing between noncoding plastome and nuclear $A d h$ sequences for phylogeny reconstruction in a recently diverged plant group. Amer. J. Bot. 85:1301-1315.

Suominen, L., Roos, C., Lortet, G., Paulin, L., and Lindstrom, K. 2001. Identification and structure of the Rhizobium galegae common nodulation genes: Evidence for horizontal gene transfer. Mol. Biol. Evol. 18:907-16.

Swofford, D. L. 2001. PAUP: Phylogenetic Analysis Using Parsimony. Version 4. Sinauer Associates, Sunderland, MA, U.S.A.

Thompson, J. D., Gibson, T. J., Plewniak, F., Jeanmougin, F., and Higgins, D. G. 1997. The ClustalX windows interface: Flexible strategies for multiple sequence alignment aided by quality analysis tools. Nucleic Acids Res. 24:4876-4882.

Van der Biezen, E. A., and Jones, J. D. G. 1998. The NB-ARC domain: A novel signaling motif shared by plant resistance gene products and regulators of cell death in animals. Curr. Biol. 8:226-227.

Wendel, J. F. 1989. New World tetraploid cottons contain Old World cytoplasm. Proc. Natl. Acad. Sci. U.S.A. 86:4132-4136.

Wendel, J. F., and Albert, V. A. 1992. Phylogenetics of the cotton genus (Gossypium L.): Character-state weighted parsimony analysis of chloroplast DNA restriction site data and its systematic and biogeographic implications. Syst. Bot. 17:115-143.

Wright, R.J., Thaxton, P. M., El-Zik, K. M., and Paterson, A. H. 1998. DSubgenome Bias of $\mathrm{Xcm}$ resistance genes in tetraploid Gossypium (cotton) suggests that polyploid formation has created novel avenues for evolution. Genetics 149:1987-1996.

Yu, Y. G., Buss, G. R., and Maroof, M. A. S. 1996. Isolation of a superfamily of candidate disease resistance genes in soybean based on a conserved nucleotide-binding site. Proc. Natl. Acad. Sci. U.S.A. 93:11751 11756.

Yu, Z. H., Park, Y. H., Lazo, G. R., and Kohel, R. J. 1998. Molecular mapping of the cotton genome: QTL analysis of fiber quality characteristics. Proc. Plant Animal Genome VI P352.

Zhang, H.-B., Choi, S., Woo, S.-S., Li, Z., and Wing, R. A. 1996. Construction and characterization of two rice bacterial artificial chromosome libraries from the parents of a permanent recombinant inbred mapping population. Mol. Breed. 2:11-24

Zhu, H., Cannon, S. B., Young, N. D., and Cook, D. R. 2002. Phylogeny and genomic organization of the TIR and non-TIR-NBS-LRR resistance gene family in Medicago trauncatula. Mol. Plant-Microbe Interact. 15:529-539.

\section{AUTHOR-RECOMMENDED INTERNET RESOURCES}

ClustalX webpage: www-igbmc.u-strasbg.fr/BioInfo/ClustalX/Top.html GeneDoc software: www.psc.edu/biomed/genedoc/ The GENSCAN program: genes.mit.edu/GENSCAN.html 